\title{
Durability of pulverised fuel ash (PFA) concrete exposed to acidic and alkali conditions
}

\author{
Saiful Baharin Duraman ${ }^{1, *}$ and Md. Fadhil Hakim Haji Omar ${ }^{2}$ \\ ${ }^{1}$ Civil Engineering Programmes, Faculty of Engineering, Universiti Teknologi Brunei, Brunei Darussalam \\ ${ }^{2}$ Student, Civil \& Structural Engineering, Faculty of Engineering, Universiti Teknologi Brunei, Brunei Darussalam
}

\begin{abstract}
Pulverised Fuel Ash (PFA) is becoming an important component in concrete due to potentially improved properties such as workability, later age strength and durability. Concrete structures may be susceptible to acid attack due to exposure to acid rain, acidic soil or polluted water. Concrete structures exposed to high alkaline environments, in addition to the alkalinity level of the cement and aggregates, may promote alkali-silica reaction (ASR) leading to swelling and reduction in durability. This study looks into the durability properties of PFA incorporated concrete at various replacement levels when exposed to highly acidic and alkali conditions. Compressive strengths and water absorption tests were compared between concrete cured under normal conditions with concrete exposed to highly acidic and highly alkali conditions. All specimens exposed to acidic conditions showed significant decreases in mass and compressive strengths compared to specimens cured normally. Higher PFA replacement resulted in improved resistance to acid attack. All specimens exposed to alkali conditions showed minor increases in mass suggesting ASR occurring. Reductions in compressive strengths were found at lower replacement levels. At higher replacement levels, increases in compressive strengths were found, suggesting the possibility of increased pozzolanic reaction of the PFA due to the high alkalinity.
\end{abstract}

\section{Introduction}

Pulverised fuel ash (PFA) or fly ash, is a waste product of coal production, and is becoming a common constituent in concrete due to the potential advantages. Even in the case of countries with no production of coal, for example Brunei Darussalam, imports fuel ash to utilise its benefits. PFA can be used to replace cement at different percentage replacement levels leading to varying strengths and other properties. High percentage replacement (beyond 30\%) is usually used in mass construction such as dams and foundations, to control temperature rise [1]. At the same time, there are also limitations when using PFA especially at higher replacement levels; these include retardation of strength development and hence, reduced early strength [2][3]. The advantages however include improved workability, enhanced long-term strength with lower water/cement ratio, reduced drying shrinkage, and extended setting time [4]. In addition, sufficiently cured concrete incorporated with PFA can possibly reduce the concrete permeability for water and aggressive chemicals and hence improve durability [5]. Durability relates to how a concrete structure can withstand extreme and abrasive conditions such as marine or highly acidic environment. Durability can be related with concrete permeability as the destructive chemicals such as chlorides and sulphates attack the concrete by entering through concrete pores. Changes in mass and strength provide good indication of changes in durability properties of concrete and have been utilized sufficiently in previous studies e.g. [6]-[9].

Concrete may be prone to acid attack since it is alkaline in nature. Concrete structures may be exposed to acid attack when there is acid rain or when the structure is constructed on polluted water or acidic soils. Concrete can also experience acid attack from air pollution due to the presence of atmospheric sulphur dioxide, carbon dioxide and nitrogen dioxides [10]. Strong acids, such as nitric acid $\left(\mathrm{HNO}_{3}\right)$ can be found in nitrifying pond of wastewater treatment plants. Many countries e.g. the US and the UK, have sewer systems which may be composed of concrete. These structures are prone to acid attack since it carries sewage which is acidic in nature.

Long-term exposure in high alkali environments, in addition to the alkalinity level of the cement and aggregates themselves, can promote alkali-silica reaction (ASR) processs leading to concrete expansion and eventually cracking allowing further deterioration processes such as reinforcement corrosion and freezethaw in cold countries to occur.

The aim of this study is to improve understanding of concrete properties incorporating PFA exposed to

\footnotetext{
* Corresponding author: saiful.duraman@utb.edu.bn
} 
acidic and alkaline environments in comparison to neat concrete (i.e. concrete with $0 \%$ PFA replacement) and PFA incorporated concrete in normal exposure conditions. Increasing levels of PFA as cement replacement are used, starting from $0 \%$ (i.e. neat concrete) up to $45 \%$ replacement. Various properties were studied; however for the purpose of this paper the compressive strength and water absorption comparisons are discussed.

\section{Literature Review}

In addition to that discussed previously, previous research done concerning the durability of PFA incorporated concrete includes that by Nath and Sarker (2011) who carried out drying shrinkage, sorptivity and rapid chloride permeability tests on $0 \%, 30 \%$ and $40 \%$ fuel ash concrete. They carried out 2 sets of experiments, Series A (varying total binder content and varying water/binder ratio) and Series B (constant total binder content and constant water/binder ratio). They determined that generally for both series A and B, concrete incorporated with fly ash showed less drying shrinkage and also give reduced sorptivity and permeability of chloride ion as compared to plain concrete. $40 \%$ fly ash led to a more positive result than that of $30 \%$.

Reddy et al. (2013) studied the durability performance of OPC mixed with various \% replacements of supplementary cementing materials (SCM) i.e. Fuel ash, Silica fume and Metakaoline, by immersing the samples in acid (5\% Hydrochloric acid), alkali (5\% sodium hydroxide), and sulphates ( $5 \%$ sodium sulphate and 5\% magnesium sulphate) for 90 days. They believe that adding SCMs can improve both durability and strength and hence prolonging the service life of concrete structures. For both their acid and alkali attack, the samples containing $20 \%$ fuel ash replacement resulted in higher mass loss and compressive strength loss compared to plain concrete. Meanwhile for sulphate attack test, the replacement of $20 \%$ fuel ash gave reduced mass loss and compressive strength loss.

Sahoo et al. (2015) conducted a study on the effect of acid, sulphate and chloride exposure on high volume fly ash (HVFA) amounting to 40\% PFA replacement, low volume fly ash (LVFA) amounting to $25 \%$ PFA replacement, and plain concrete with different water curing ages $(28,56,90$ and 180 days). The chemicals used were 5\% Sodium Chloride, 5\% Sodium Sulphate and $1 \%$ Sulphuric Acid in separate containers. Loss in compressive strength and mass were recorded. They found out that after 56 days of curing, LVFA samples gave better resistance than the control and HVFA samples. However, when it comes to extended curing of 90 and 180 days, HVFA samples showed the greatest resistance to the chemical attack while the plain concrete samples showed a massive loss in strength.

Aydin et al. (2007) studied the effects of incorporating Class $\mathrm{C}$ fuel ash in concrete on mechanical properties and sulphuric acid resistance. The design mixes used consist of up to $70 \%$ of FA replacement with
$10 \%$ increments. The experiments were done in two different curing methods, i.e. standard water curing and steam curing. Each sample with ages 1, 3, 7, 28, 56 and 90 days were immersed in 5\% sulphuric acid for 60 days. Percentage mass loss and strength loss were measured. The researchers found out that the strength loss after acid exposure of steam curing samples drop from $58 \%$ (FA0) to $21 \%$ (FA70). Meanwhile, there were almost similar strength and mass loss for water curing samples with increasing PFA replacement. Therefore, they concluded that the acid resistance of steam cured samples improved with the inclusion of PFA however the PFA gave no effect on water curing samples.

Balakrishnan and Awal (2014) investigated the durability performance of high volume fly ash (HVFA) by conducting chloride ion penetration test, acid attack and sulphate attack test to $0 \%, 40 \%, 50 \%$ and $60 \%$ fly ash replacement by weight of cement. The researchers found out that the more fly ash is used in concrete mix, the lesser the penetration of chloride ion. They also gave reduced mass and strength loss upon exposure in acid solution. Furthermore, HVFA mix were completely unaffected by sulphate solution whereas the $0 \%$ PFA mix were completely deformed.

Naik, Singh and Hossain (1996) studied the effects of using class $\mathrm{C}$ fly ash with respect to concrete permeability. They conducted air permeability, water permeability and chloride ion permeability tests on PFA concrete with varying percentage replacements between $0 \%$ to $70 \%$. For the water permeability test, they used the Figg method i.e. measuring the time in seconds a sample can absorb $0.02 \mathrm{ml}$ of water. The permeability of water cured samples at 14,28 and 91 days were measured. At relatively early age of 14 days, the concrete samples with $0 \%$ PFA showed best resistance in water permeability giving 386 seconds. For later age of 91 days, 35\% PFA gave the highest water permeability resistance taking 1713 seconds. At 91 days, it can also be seen that even greater amount of cement replacement leads to higher water permeability. The authors concluded this is due to poor concrete microstructure which resulted from reduced amount of calcium silicate hydrate gel (C-S-H) produced due to low cement volume.

\section{Methodology}

\subsection{Overview of Mixes}

Mixes were designed in accordance to the British DoE Method of Mix Design. The neat concrete mixes were designed for medium slump (i.e. 30-60 mm slump range) and 0.6 water-binder ratio, using Class 62.5 ordinary Portland cement (OPC) as main binder, Class F PFA as cement replacement, $10 \mathrm{~mm}$ nominal size gravel as coarse aggregate (CA) and $F$ classification fine aggregate (FA). PFA replacement was via weight replacement at levels of $0 \%$ (i.e. neat concrete), $15 \%$, $30 \%$ and $45 \%$, and mixes were labelled PFA0, PFA 15 , PFA30 and PFA45 mixes respectively. The mix proportions used are summarised in Table 1. Unless 
stated otherwise, the specimens were water-cured immediately after the demoulding process. To ensure consistency of results, all specimens for a particular mix were done from the same mix.

Table 1. Mix Proportions Used (in $\mathrm{kg} / \mathrm{m}^{3}$ )

\begin{tabular}{|l|l|c|c|c|c|c|c|}
\hline \multirow{2}{*}{ Mix } & \multirow{2}{*}{ W/B } & \multirow{2}{*}{$\begin{array}{c}\text { PFA } \\
\%\end{array}$} & & \multicolumn{5}{|c|}{ Mix Proportions $\left(\right.$ in $\left.\mathrm{kg} / \mathrm{m}^{3}\right)$} \\
\cline { 4 - 8 } & & & OPC & PFA & Water & CA & FA \\
\hline PFA0 & 0.6 & 0 & 383 & - & 230 & 1195 & 562 \\
\hline PFA15 & 0.6 & 15 & 325.5 & 57.5 & 230 & 1195 & 562 \\
\hline PFA30 & 0.6 & 30 & 268 & 115 & 230 & 1195 & 562 \\
\hline PFA45 & 0.6 & 45 & 210.6 & 172.4 & 230 & 1195 & 562 \\
\hline
\end{tabular}

\subsection{Compressive Strength Tests}

Compressive strength tests were done according to BS EN 12390-3:2009. The mean compressive strength for a mix at a specific age was the average compressive strength at failure of 3 cubes of dimensions $100 \mathrm{~mm}$. The mean compressive strengths were determined for each mix at ages 3, 7, 28, 59 and 91 days. Compressive strengths were determined at 3,7 and 28 days to provide good representation of the strength progression up to 28 days. Results at 59 and 91 days gave good representation of the later age strength progression, and comparison with the specimens exposed to acid or alkali, as explained later. It was not feasible to determine results later than 91 days due to the project duration limitations.

\subsection{Water Absorption Tests}

Water absorption tests were done according to BS1881122:2011. Due to limitations in volume, tests were conducted only at one age for all mixes. Water absorption at 28 days was considered the optimum age since would provide a norm representation of the concrete properties. The mean water absorption for a mix was therefore the average water absorption results of 2 specimens at 28 day age.

\subsection{Acid Attack Tests}

At 28 day age, cube specimens were air dried for 24 hours following normal water-curing. The specimens were then immersed in acidic solution (5\% hydrochloric $(\mathrm{HCl})$ acid, 95\% water). The initial mass was measured prior to immersion. The specimens were immersed for a period of 30 days. After the immersion period, each specimen was rinsed lightly using water, ensuring no mass loss occurred due to the rinsing process, and final mass measured. Percentage (\%) mass loss (and subsequently \% mean mass loss) based on the original mass could thus be calculated.

The mean compressive strength at failure for each mix was determined. Percentage (\%) loss of compressive strength was then determined by comparing against the mean compressive strength of the mix when normally cured at 59 day age.

\subsection{Alkali Attack Tests}

The methodology for exposing the specimens to alkali reaction attack was as per that described previously for Acid Attack Tests; the only difference was that the specimens were immersed in alkali solution (5\% sodium hydroxide $(\mathrm{NaOH}), 95 \%$ water). Similarly, percentage (\%) mass loss (or gain) and percentage (\%) compressive strength loss (or gain) was determined as per previously described.

\section{Results and Discussions}

\subsection{Compressive Strength}

The mean compressive strength results are summarised in Table 2 and graphically shown in Figure 1. The mix with $0 \%$ PFA i.e. PFA0 Mix, had the highest early age strength (at 3 and 7 days) followed by the PFA15, PFA30 and PFA45 mixes. OPC used as sole binder allowed higher cement hydration at early age. With increasing PFA replacement, the hydration slowed down resulting in lower early age strength for the PFA30 and PFA45 mixes. Although the PFA0 Mix had the highest 28 days strength compared to other mixes, strength development started to slow down after 59 day age, whilst strength continued for the other mixes indicating hydration of the PFA progressing at later ages.

The PFA45 Mix, which had the highest PFA replacement, had the lowest early age strength but if the strength development graph (Figure 1) of PFA45 were to be forecasted beyond 91 day age, its compressive strength is predicted to continuously increase more than the other mixes. The PFA30 and PFA45 mixes showed slower strength development than the PFA0 and PFA15 mixes due to lower cement volume and hence further slowing down the hydration process.

Table 2. Compressive Strength (in MPa) Results at Specified Ages (in days)

\begin{tabular}{|l|c|c|c|c|c|}
\hline \multirow{2}{*}{ Mix } & \multicolumn{5}{|c|}{ Age (in days) } \\
\cline { 2 - 6 } & 3 & 7 & 28 & 59 & 91 \\
\hline PFA0 & 20.96 & 27.69 & 36.99 & 42.67 & 34.89 \\
\hline PFA15 & 16.00 & 21.69 & 32.25 & 43.41 & 38.65 \\
\hline PFA30 & 14.42 & 17.94 & 32.60 & 36.50 & 41.94 \\
\hline PFA45 & 8.53 & 11.20 & 21.27 & 24.54 & 35.95 \\
\hline
\end{tabular}




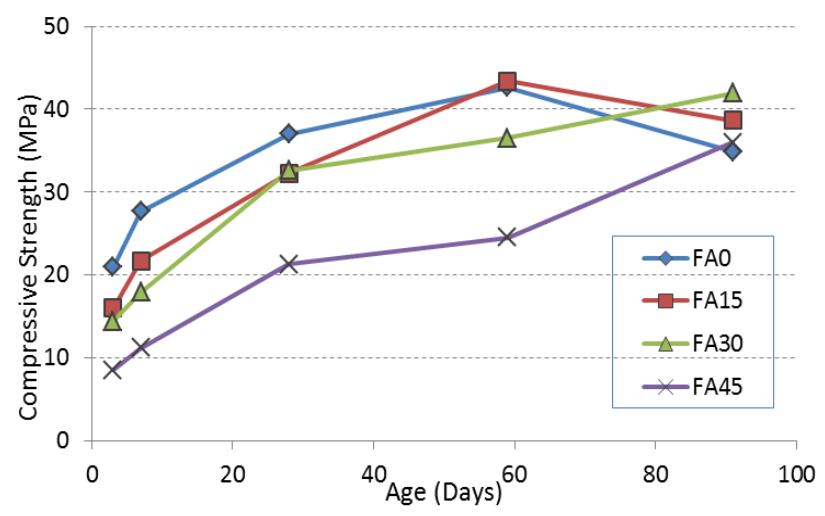

Fig. 1. Mean Compressive Strength Development at Different PFA Replacement Levels

\subsection{Water Absorption}

From the water absorption graph in Figure 2, the PFA0 Mix is shown to have the highest water absorption (3.55\%) followed by a significant reduction $(2.43 \%)$ when PFA was incorporated at $15 \%$ replacement level. At increasing replacement levels, the water absorption results were almost consistent, at 2.18 and $2.36 \%$ for the PFA30 and PFA45 mixes respectively. The results coincide with Naik, Singh and Hossain (1996), which was attributed to the slower development of the C-S-H gel which is responsible for the concrete's permeability and durability. The C-S-H gel was not produced in large volume and hence caused poor concrete microstructure leading to increase in permeability.

The results and trends obtained justify the decision to determine water absorption properties at 28 day age, due to mix volume limitations as previously explained. At the same time however, comparisons at other ages, more especially at early age (e.g. 3 day age) and at later ages (e.g. 91 day age) would provide a better understanding of the water absorption and subsequently permeability properties of PFA concrete and it is therefore recommended that water absorption values at other ages be done for greater understanding of the durability properties.

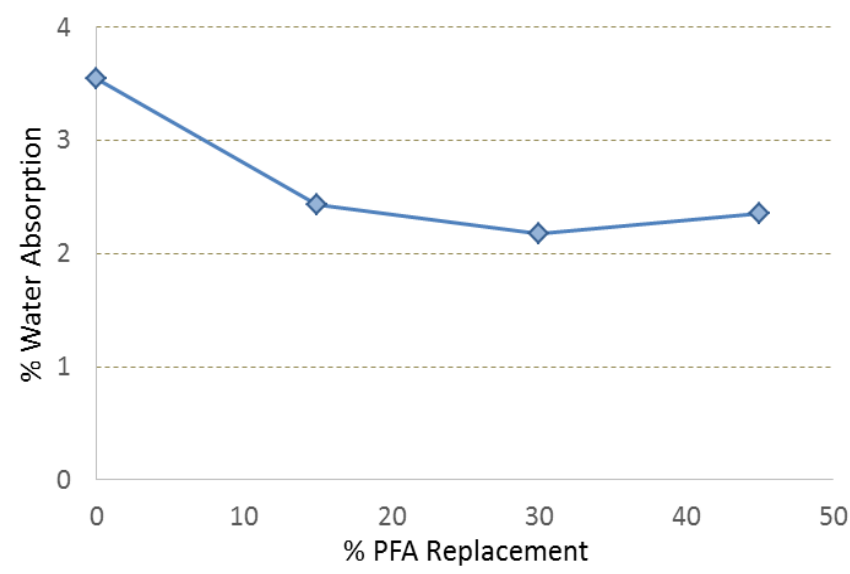

Fig. 2. Water Absorption Results at 28 Day Age With Varying PFA Replacement Levels

\subsection{Acid Attack}

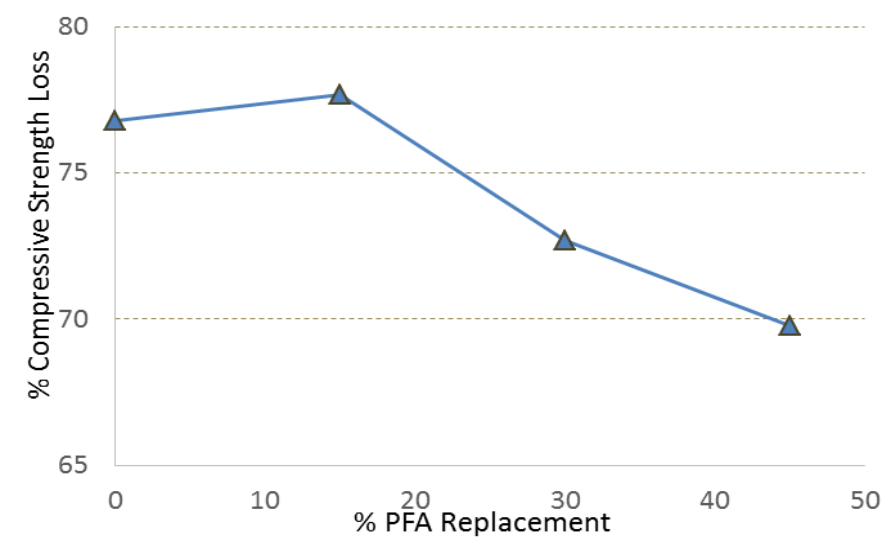

Fig. 3. Percentage Compressive Strength Loss From Acid Attack

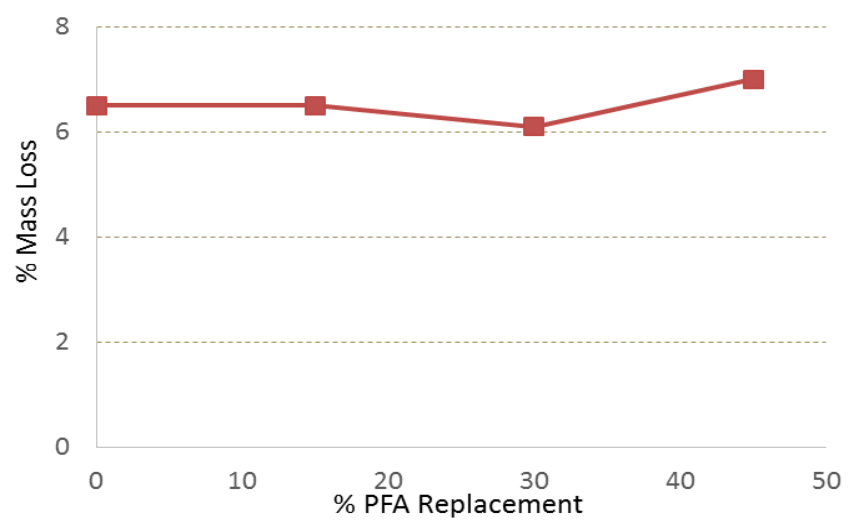

Fig. 4. Percentage Mass Loss From Acid Attack

From Figure 3, the compressive strength loss for the PFA15 and PFA0 mixes are comparatively similar (76.8 and $77.7 \%$ respectively). One possible reason is that the $15 \%$ replacement was relatively low thus having less effect on acidic attack resistance. At higher levels, the compressive strength loss however decreased, suggesting incorporation of PFA in concrete may improve resistance to acid attack. It is likely that the acid has increased the leaching process of the calcium hydroxide $(\mathrm{CH})$ in the concrete. The reduced $\mathrm{CH}$ and subsequently higher C-S-H from the PFA hydration process has likely improved the acid attack resistance. Even higher replacement levels may result in improved durability and acid resistance; however, the potential drawbacks with higher replacement levels e.g. retardation of early age compressive strength, must be considered.

All of the specimens experienced mass loss at relatively similar percentage as shown in Figure 4, which shows that regardless of percentage cement replacement with PFA up to a certain level, the mass loss will still be approximately similar. The results are in agreement with Aydin et al. (2007) regarding mass loss of water cured samples. Figure 5 below shows the after effects of concrete cubes exposed to acidic conditions. The surface is shown to be deteriorated and aggregates exposed. Figure 6 provides indication of the penetration depth of the acid attack. 


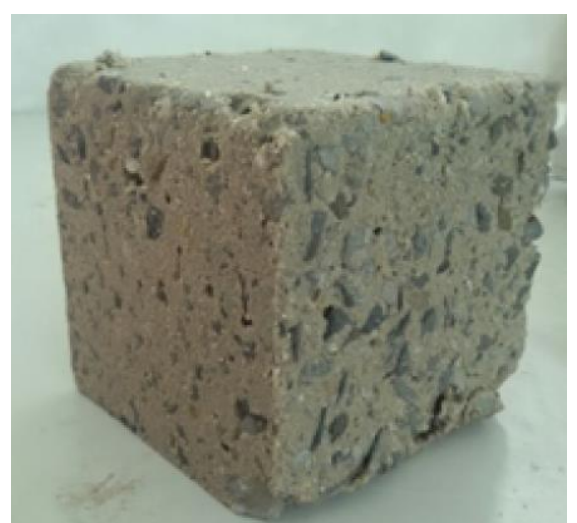

Fig. 5. Surface Deterioration of Concrete After Acid Attack

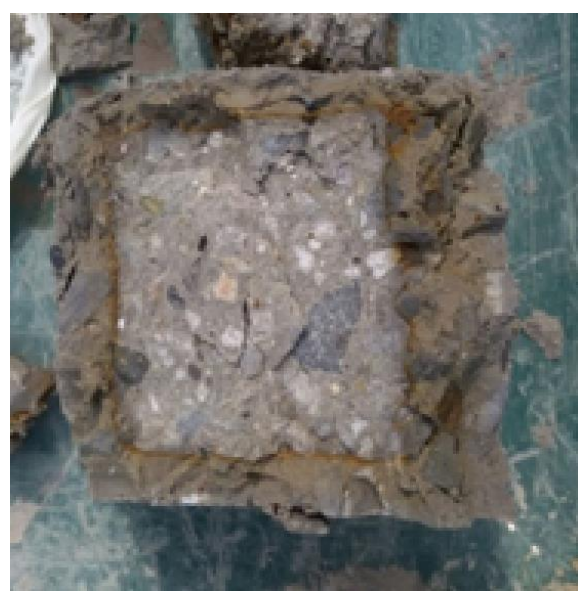

Fig. 6. Penetration Depth After Acid Attack

\subsection{Alkali Attack}

At all replacement levels, the specimens experience mass gain, albeit minor, at approximately $0.5 \%$ (the actual range is 0.5 to $0.54 \%$ ). As seen graphically in Figure 7 , this mass increase can be summarised to be minor, and consistent at all replacement levels used. Figure 8 shows the specimens after exposure to alkali and was similar in nature to normally cured specimens.

As shown in Figure 9, 15\% PFA replacement experienced the highest compressive strength loss at $15.9 \%$, albeit $0 \%$ PFA replacement was relatively close at $12.9 \%$. More interesting though is that after a certain percentage replacement level, in this case at $30 \%$ replacement, the compressive strength starts to increase when exposed to alkali as compared to normally cured. At $45 \%$ replacement, the compressive strength has increased by $32.1 \%$ compared with normally cured.

It is possible that alkali exposure (in this case $\mathrm{NaOH}$ ) has led to ASR occurring as expected. However at the same time, the higher alkalinity has increased the PFA pozzolanic reaction rate leading to increased C-S-H production as compared to normally cured. This would explain the gain in compressive strength as compared to normally cured. According to the results, 30\% PFA replacement level appears to be the pessimum level between ASR and increase of pozzolanic activity. The duration of the study was however short, and it is therefore recommended that further tests, including tests at other ages (i.e. at other levels of hydration reaction), be done to further understand this occurrence and support the reasons given. For comparison purposes, Reddy et al. (2013) immersed the specimens for 90 to 100 days and observed swelling due to alkali attack.

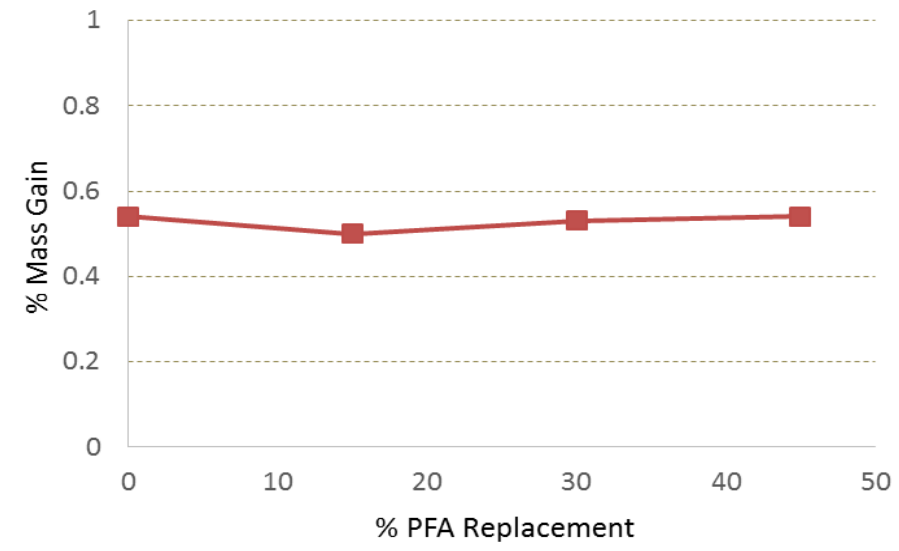

Fig. 7. Percentage Mass Gain From Alkali Attack

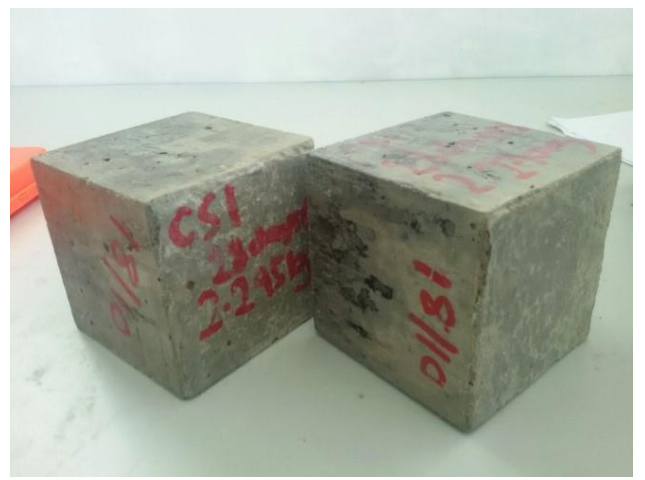

Fig. 8. Specimens After Alkali Attack

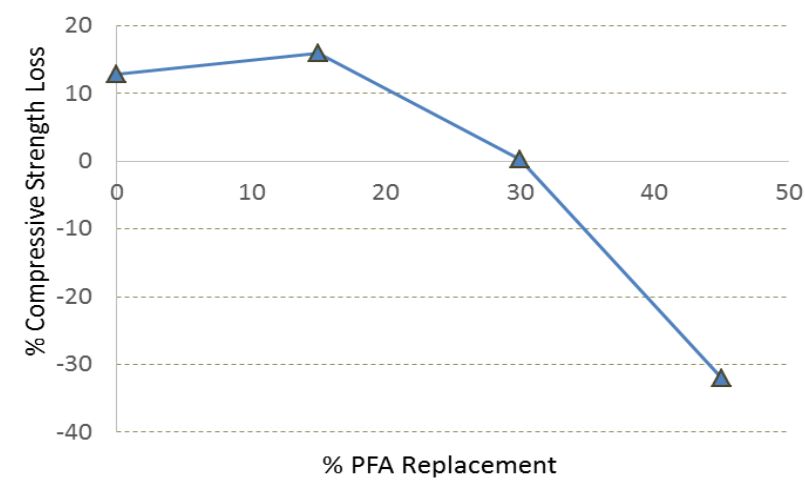

Fig. 9. Percentage Compressive Strength Loss Due to Alkali Attack

(Note: +ve value indicates strength loss and-ve value indicates strength gain) 


\section{Conclusions and Recommendations}

The results of this study showed reduced permeability and improved later age compressive strength with incorporation of PFA in concrete. Specimens exposed to acidic conditions resulted in significantly decreasing mass and compressive strength compared to normally cured specimens, although higher PFA replacement resulted in improved resistance. Specimens exposed to alkali conditions showed minor increases in mass. Reductions in compressive strengths compared to the normally cured specimens were found suggesting alkalisilica reaction (ASR) occurring. At higher PFA replacement levels however, the compressive strengths were found to be greater than for normally cured specimens, suggesting increased rate of pozzolanic reaction from the PFA.

There appears to be optimum limits for PFA replacement depending on the environment the concrete is exposed to. Based on the results of this study using the tests and conditions utilized, the optimum percentage replacement level of PFA with respect to optimum permeability, resistance to acid and alkali attacks, and compressive strength is between $22 \%$ to $37 \%$ replacement.

\section{References}

1. M. D. A. Thomas, "Optimizing the Use of Fly Ash in Concrete," Portl. Cem. Assoc., 24, (2007).

2. K. G. Babu and G. S. N. Rao, "Early Strength Behaviour of Fly Ash Concretes," Cem. Concr. Res., 24, 277-284, (1994).

3. P. S. B. P. Duraman, "Microstructure and Properties of Steel-Reinforced Concrete Systems Hydrated at 20C and 38C," University of Leeds, UK, (2007).

4. S. McCraven, "The Future of Fly Ash Use in Concrete," National Precast Concrete Association, (2013).

5. A. Rosenberg, "Using Fly Ash in Concrete," National Precast Concrete Association, (2010).

6. M. V. S. Reddy, Ramana Reddy, K Madan Mohan Reddy, and C M Ravi Kumar, "Durability Aspects of Standard Concrete," Int. J. Struct. Civ. Eng. Res., 2, 40-46 (2013).

7. S. Sahoo, B. B. Das, A. K. Rath, and B. B. Kar, "Acid, Alkali and Chloride Resistance of High Volume Fly Ash Concrete," Indian J. Sci. Technol., 8, 326-332, (2015).

8. S. Aydın, H. Yazıcı, H. Yiğiter, and B. Baradan, "Sulfuric acid resistance of high-volume fly ash concrete," Build. Environ., 42, 717-721, (2007).

9. B. Balakrishnan and A. S. M. A. Awal, "Durability properties of concrete containing high volume Malaysian fly ash," Int. J. Res. Eng. Technol., 3, 529-533 (2014).
10. V. Zivica and A. Bajza, "Acidic attack of cement based materials - A review. Part 1. Principle of acidic attack," Constr. Build. Mater., 15, 331340, (2001).

11. P. Nath and P. Sarker, "Effect of fly ash on the durability properties of high strength concrete," in Procedia Engineering, 14, 1149-1156, (2011).

12. T. R. Naik, S. S. Singh, and M. M. Hossain, "Permeability of High-Strength Concrete Containing Low Cement Factor," J. Energy Eng., 122, 21-39, (1996) 